\title{
Diagnosis and Treatment of Dyssynergic Defecation
}

\author{
Satish S C Rao ${ }^{1 *}$ and Tanisa Patcharatrakul ${ }^{1,2}$ \\ ${ }^{1}$ Division of Gastroenterology and Hepatology, Department of Internal Medicine, Augusta University, Augusta, Georgia, USA; and ${ }^{2}$ Division of \\ Gastroenterology, Department of Medicine, King Chulalongkorn Memorial Hospital, Thai Red Cross Society, Bangkok, Thailand
}

Dyssynergic defecation is common and affects up to one half of patients with chronic constipation. This acquired behavioral problem is due to the inability to coordinate the abdominal and pelvic floor muscles to evacuate stools. A detailed history, prospective stool diaries, and a careful digital rectal examination will not only identify the nature of bowel dysfunction, but also raise the index of suspicion for this evacuation disorder. Anorectal physiology tests and balloon expulsion test are essential for a diagnosis. Newer techniques such as high-resolution manometry and magnetic resonance defecography can provide mechanistic insights. Recently, randomized controlled trials have shown that biofeedback therapy is more effective than laxatives and other modalities, both in the short term and long term, without side effects. Also, symptom improvements correlated with changes in underlying pathophysiology. Biofeedback therapy has been recommended as the first-line of treatment for dyssynergic defecation. Here, we provide an overview of the burden of illness and pathophysiology of dyssynergic defecation, and how to diagnose and treat this condition with biofeedback therapy.

(J Neurogastroenterol Motil 2016;22:423-435)

\section{Key Words}

Constipation; Defecation; Laxatives

\section{Introduction}

Today, it is increasingly recognized that pelvic floor dysfunction can cause constipation and difficulty with defecation. ${ }^{1}$ Preston and Lennard-Jones ${ }^{2}$ first described the association of paradoxical anal contraction during attempted defecation in patients with constipation and coined the term "anismus". Subsequently, several terms have been used to describe this entity, including anismus, ${ }^{2}$ pelvic floor dyssynergia, ${ }^{3}$ obstructive defecation, ${ }^{4}$ paradoxical puborectalis contraction, ${ }^{5}$ pelvic outlet obstruction, ${ }^{6}$ and spastic pelvic floor syndrome. ${ }^{7}$ Pelvic floor is a complex muscular apparatus that serves three important functions, namely, defecation, micturition, and sexual function. Terms that include pelvic floor imply that this problem affects the entire pelvic floor, but constipated patients rarely report sexual or urinary symptoms. ${ }^{8}$ Because the chief pathophysiology involves incoordination of the process of defecation, the term dyssynergic defecation aptly describes this condition ${ }^{1}$ and has been endorsed by the Rome criteria. ${ }^{9}$

\section{Epidemiology}

The global prevalence of chronic constipation in the community varies from $11 \%$ to $18 \% .^{10}$ These prevalence have been underestimated because most patients do not seek health care. ${ }^{11}$ The natural history is not known and it may not resolve quickly, since most had

Received: April 10, 2016 Revised: None Accepted: April 27, 2016

() This is an Open Access article distributed under the terms of the Creative Commons Attribution Non-Commercial License (http://creativecommons. org/licenses/by-nc/4.0) which permits unrestricted non-commercial use, distribution, and reproduction in any medium, provided the original work is properly cited.

${ }^{*}$ Correspondence: Satish S C Rao, MD, PhD, FRCP (LON)

Division of Gastroenterology and Hepatology, Augusta University, AD 2238, Digestive Health Center, 1481 Laney-Walker Blvd, Augusta, GA 30912, USA

Tel: +1-706-721-2238, Fax: +1-706-721-0331, E-mail: srao@augusta.edu 
similar symptoms one year apart, and one half had symptoms for 5 years or more. ${ }^{12}$ Patients with persistent constipation have more laxative use, more frequent doctor visits, and more somatic symptoms than those with nonpersistent constipation. ${ }^{13}$ Constipation is more common in women with an estimated female:male ratio of 2.2:1. ${ }^{10}$ Its prevalence increases with advancing age, particularly after age $65 .{ }^{10}$ African Americans, ${ }^{10}$ lower socioeconomic status, ${ }^{10}$ pregnancy, ${ }^{14}$ and neurological diseases including Parkinson's disease and multiple sclerosis ${ }^{15}$ have high prevalence of constipation. Dyssynergic defecation is detected in $27-59 \%$, and slow colonic transit in $3-47 \%$ of patients, and an overlap of dyssynergic defecation and slow colonic transit or constipation-predominant irritable bowel syndrome (IBS) was commonly present. ${ }^{16-18}$

\section{Economic and Social Impact}

Chronic constipation has a significant impact on the utilization of healthcare resources, including the cost of inpatient and outpatient care, laboratory tests, and diagnostic procedures. ${ }^{19,20}$ It affects daily life especially in those with abdominal symptoms ${ }^{21}$ and resulted in 13.7 million days of restricted activity; missing work or school in $12 \%$ and impaired ability to work in $60 \%$ of patients. ${ }^{20}$ In the United States, the direct expenditure per-patient for constipation which includes medications, hospitalizations, out-patient services, emergency visits, and laboratory tests ranged from $\$ 1912$ to $\$ 7522$ per year ${ }^{19}$ and increased several-fold between 1997 and $2010 .^{22}$ Moreover, a study revealed that up to $50 \%$ of chronic constipation and IBS patients use alternative or non-prescription medications, especially by women and patients with higher education. ${ }^{19}$ Hence, subtype differentiation, especially identifying dyssynergic defecation, and providing a specific treatment such as biofeedback therapy, can minimize laxative usage and optimize health care utility.

\section{Psychological Distress, Abuse, and Impact on Quality of Life}

Constipation is associated with increased psychological distress. Several studies have shown a higher prevalence of anxiety, depression, obsessive compulsiveness, psychoticism, and somatization. ${ }^{24}$ Furthermore, paranoid ideation and hostility subscores were higher in patients with dyssynergia than those with slow transit constipation (STC) or healthy controls, providing evidence for significant psychological distress, more so in subjects with dyssynergia than patients with STC. ${ }^{24}$

Sexual abuse was reported by $22-48 \%$ of subjects, mostly women, whereas physical abuse was reported by $31-74 \%$ of constipated subjects. $^{25,26}$ There was greater incidence of sexual abuse in women with pelvic floor dyssynergia. ${ }^{26}$ Also, patients with abuse were more likely to seek healthcare and report feelings of incomplete evacuation or urge to defecate, but did not demonstrate rectal hypersensitivity. $^{27}$

Patients with dyssynergia also showed significant impairment of health-related quality of life. ${ }^{24,25}$ Some domains of quality of life were more affected in patients with dyssynergia than STC, ${ }^{24}$ suggesting that dyssynergia is associated with greater impact on quality of life. Also, psychological distress and lower quality of life were strongly correlated, suggesting that these dysfunctions have synergistic effects on bowel function. ${ }^{24,25}$

\section{Etiology/Pathophysiology}

The etiology of dyssynergic defecation is unclear. In a prospective survey of 118 patients with dyssynergia, we found that the problem began during childhood in $31 \%$ of patients, and after a particular event, such as pregnancy, trauma, or back injury in $29 \%$ of patients, and there was no cause in $40 \%$ of patients. ${ }^{25}$ Thus, two thirds acquired this condition during adulthood. In this group, 17\% reported a history of sexual abuse, $43 \%$ the frequent passage of hard stools, and $16 \%$ intermittent passage. Thus, excessive straining to expel hard stools, over time, may also lead to dyssynergic defecation.

\section{Pathophysiology}

Earlier studies suggested that paradoxical anal contraction or involuntary anal spasm during defecation may cause this problem. ${ }^{2}$ Consequently, myectomy of the anal sphincter was performed, but only 10 to $30 \%$ of patients improved. ${ }^{28}$ Likewise, paralyzing the anal sphincter muscle with Botulinum toxin injections produced minimal improvement. ${ }^{29}$ Hence, either spasm or inability to relax the external anal sphincter is unlikely to be the sole mechanism that leads to dyssynergic defecation.

A prospective study, ${ }^{4}$ showed that most patients with dyssynergic defecation demonstrate the inability to coordinate the abdominal, rectoanal and pelvic floor muscles to facilitate defecation. This failure of rectoanal coordination consists of inadequate propulsive force, paradoxical anal contraction or inadequate anal relaxation. Thus, incoordination or dyssynergia of the muscles that are involved in defecation is primarily responsible for this condition. In addition, $50-60 \%$ of patients also demonstrate an impaired rectal sensation. ${ }^{4}$ Recently, a large controlled study showed that 3 phenotypes; high anal sphincter pressure at rest and during defecation, inadequate propulsive force, and hybrid of both disturbance, can discriminate among patients with normal and abnormal balloon expulsion times. 
These three phenotypes were uncorrelated, suggesting that the pathophysiology of dyssynergic defecation and inadequate propulsive force may be distinct. ${ }^{30}$

\section{Clinical Features}

Patients with dyssynergic defecation present with a variety of bowel symptoms. Often, patients do not volunteer or misrepresent their symptoms. For example, patients do not readily admit that they use digital maneuvers to disimpact stool or splint their vagina to facilitate defecation. However, by establishing a trustworthy relationship or through the help of symptom questionnaires or stool diaries, it may be possible to identify the precise nature of their bowel dysfunction. It is essential to determine this because only then can one approach this problem more rationally. In a prospective study, excessive straining was reported by $85 \%$, a feeling of incomplete evacuation by $75 \%$, the passage of hard stools by $65 \%$, and a stool frequency of less than 3 bowel movements per week by $62 \%$ of patients. ${ }^{25}$ In addition, $66 \%$ of patients used digital maneuvers to facilitate defecation. In another study of 134 patients, two or fewer stools/week, laxative dependence and constipation since childhood was associated with slow transit constipation, whereas backache, heartburn, anorectal surgery, and a lower prevalence of normal stool frequency was reported by patients with pelvic floor dysfunction. ${ }^{31}$ They concluded that symptoms are good predictors of transit time but poor predictors of pelvic floor dysfunction. ${ }^{31}$ A study of 190 constipated patients showed that stool frequency alone was of little value in constipation and not specific to slow colonic transit, whereas a sense of obstruction/digital evacuation was specific but not sensitive for dyssynergic defecation. ${ }^{32}$ They also concluded that symptoms alone cannot differentiate between the slow transit constipation and dyssynergic defecation. ${ }^{32}$ Patients with dyssynergia may have abdominal pain, abdominal discomfort or anorectal pain as their prominent symptoms. Several studies have shown that a substantial number of patients with dyssynergic defecation have overlapping IBS features, ${ }^{18,33}$ and could be effectively treated with biofeedback therapy similar to patients with isolated dyssynergia. ${ }^{18}$ Also, IBS symptoms significantly improved after dyssynergia treatment with biofeedback therapy. ${ }^{18}$ In addition, a large prospective trial in patients with suspected levator ani syndrome without constipation has shown that $85 \%$ of these patients had physiologic features of dyssynergic defecation. ${ }^{34}$ Also, they were effectively treated with biofeedback therapy, especially in patients with tenderness of the levator ani muscles. ${ }^{34}$ Many patients with the solitary rectal ulcer syndrome also exhibit dyssynergic defecation. ${ }^{35}$
Patients with defecation disorders also have several psychological issues ${ }^{24}$ such as obsessive compulsive disorder where the patient believes that having a bowel movement everyday or sometimes several times per day is the norm. A deviation from this process compels the individual to use laxatives, enemas, suppositories, or any other means to achieve an unphysiological pattern of bowel movement. Others have phobia for painful defecation or stool impaction. This particularly affects children, who then learn quickly to exploit stooling habit for seeking attention. ${ }^{36}$ The problem may also be driven by psychosocial issues such as inter-parental or parental/ child conflicts or sibling rivalry. It has been shown that social learning from parental reactions to symptom complaints may alter illness behavior and the manifestation of functional gastrointestinal disorders. ${ }^{37}$ Finally, patients with bulimia or anorexia nervosa and those with a history of physical or sexual abuse may also develop profound defecation problems. ${ }^{38}$

\section{Diagnostic Procedures}

\section{General Issues}

The first step in making a diagnosis of dyssynergic defecation is to exclude an underlying metabolic or pathologic disorder. STC may co-exist in up to two thirds of patients with dyssynergic defeca$\operatorname{tion}^{25,39}$ and hence, an assessment of colonic transit is useful. An evaluation of the distal colonic mucosa through flexible sigmoidoscopy may provide evidence for chronic laxative use, may reveal melanosis coli or other mucosal lesions such as solitary ulcer syndrome, inflammation or malignancy. Differential diagnosis includes many structural or functional abnormalities that may also lead to an evacuation disorder such as rectoceles, hypertensive anal sphincters, hemorrhoids, anal fissures, anorectal neoplasias, rectal prolapse, proctitis, excessive perineal descent, and mucosal intussusception. These conditions can be readily identified through appropriate testings.

\section{Digital Rectal Examination}

A careful perianal and digital rectal examination (DRE) is not only important but often the most revealing part of a clinical evaluation. DRE may reveal a stricture, spasm, tenderness, mass, blood or stool. If stool is present, its consistency should be noted and the patient should be asked if they are aware of its presence. A lack of awareness of stool in the rectum may suggest rectal hyposensitivity. It is useful to assess the resting and squeeze tone of the anal sphincter and puborectalis muscle by asking the subject to squeeze. More 
importantly, the subject should be asked to push and bear down as if to defecate. During this maneuver, the examiner should perceive relaxation of the external anal sphincter and/or the puborectalis muscle, together with perineal descent, and simultaneously a hand placed on the abdomen should feel a strong abdominal push effort. An absence of these normal findings should raise the index of suspicion for an evacuation disorder such as dyssynergic defecation. ${ }^{40}$ DRE has a sensitivity of $75 \%$ and specificity of $87 \%$ for identifying dyssynergia as predicted by anorectal manometry. ${ }^{40}$ Even though DRE is a useful clinical tool, a survey study of 652 physicians and final year medical students showed that there is a lack of knowledge on how to perform a comprehensive evaluation and it is underutilized in clinical practice. ${ }^{41} \mathrm{~A}$ majority of physicians were uncomfortable to perform a DRE and were unsure of making a diagnosis on their findings. ${ }^{41}$ To improve diagnosis, training in DRE is important.

\section{Anorectal Manometry}

Anorectal manometry provides assessment of dyssynergia and its subtypes together with an assessment of rectal sensation, reflexes, and compliance. ${ }^{39}$ It is essential for a diagnosis of dyssynergic defecation. ${ }^{9}$ First, it excludes the possibility of Hirschsprung's disease. Second, it detects abnormalities during attempted defecation. Normally, when a subject bears down or attempts to defecate, there is a rise in rectal pressure, which is synchronized with a relaxation of the external anal sphincter (Fig. 1). This maneuver is under voluntary control and is primarily a learned response. The inability to perform this coordinated movement represents the key pathophysiologic abnormality in dyssynergic defecation. This may be due to inadequate pushing force, paradoxical anal sphincter contraction, impaired anal sphincter relaxation, or a combination of these mechanisms. Based on these features, at least four types of dyssynergic defecation have been recognized (Fig. 1).

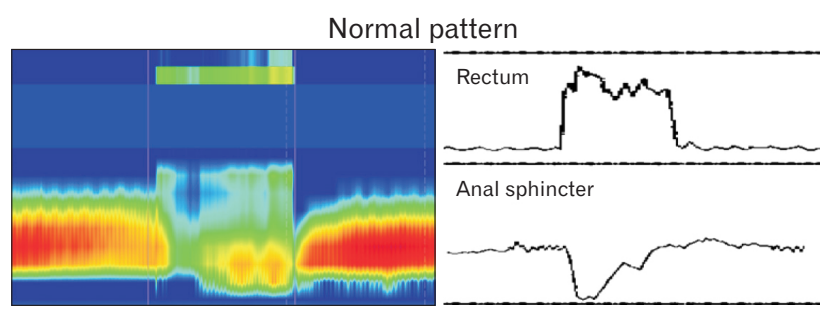

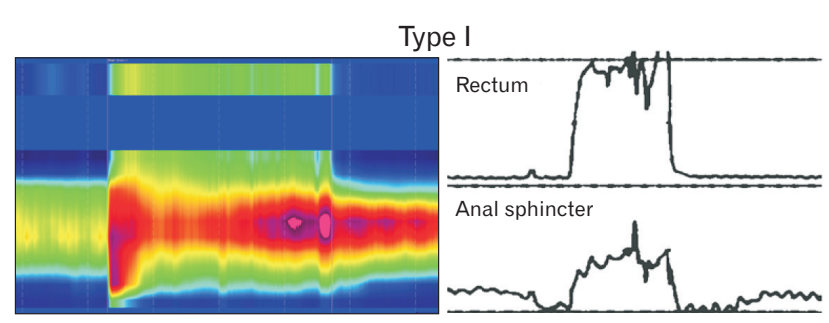

Type III
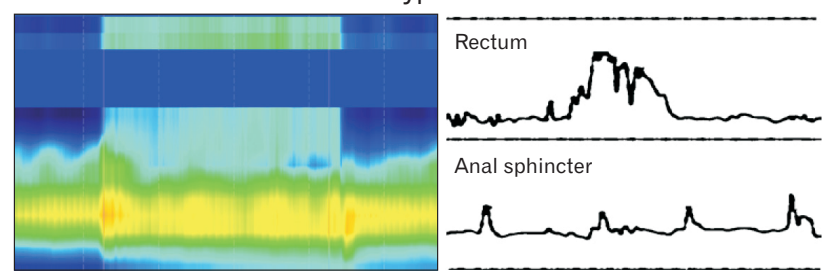

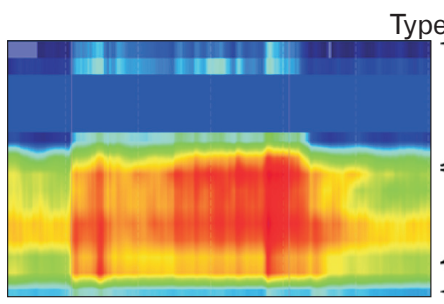

Type II

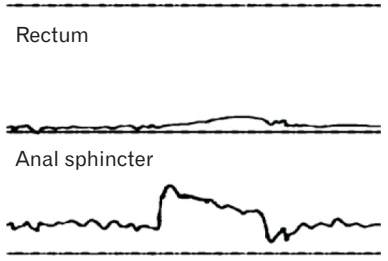

Type IV

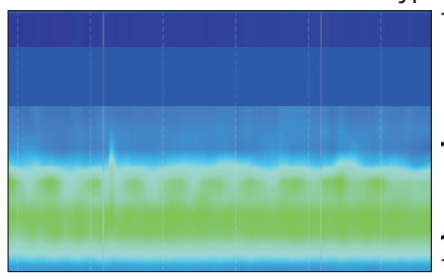

Rectum

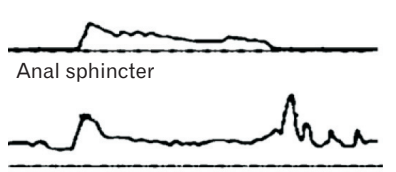

Figure 1. This series of conventional manometry and high-resolution manometry tracings reveals patterns that are commonly seen during attempted defecation in a healthy individual (top panel) and in patients with dyssynergic defecation. In a normal pattern of defecation, the subject can generate a good pushing force (increase in intra rectal pressure) and simultaneously relax the anal sphincter. In contrast, patients with dyssynergic defecation exhibit one of four abnormal patterns of defecation. In type I dyssynergia, the subject can generate an adequate propulsive force (rise in intra rectal pressure $\geq 40 \mathrm{mmHg}$ ) along with paradoxical increase in anal sphincter pressure. In type II dyssynergia, the subject is unable to generate an adequate propulsive force; additionally there is paradoxical anal contraction. In type III dyssynergia, the subject can generate an adequate propulsive force but there is either absent relaxation (a flat line) or inadequate $(\leq 20 \%)$ relaxation of anal sphincter. In type IV dyssynergia, the subject is unable to generate an adequate propulsive force together with an absent or inadequate relaxation of anal sphincter. 
Type I: The patient can generate an adequate pushing force (rise in intraabdominal pressure) along with a paradoxical increase in anal sphincter pressure.

Type II: The patient is unable to generate an adequate pushing force (no increase in intrarectal pressure) but exhibit a paradoxical anal sphincter contraction.

Type III: The patient can generate an adequate pushing force (increase in intrarectal pressure) but, either has absent or incomplete $(<20 \%)$ anal sphincter relaxation (ie, no decrease in anal sphincter pressure).

Type IV: The patient is unable to generate an adequate pushing force and demonstrates an absent or incomplete anal sphincter relaxation.

Four additional subtypes were described recently by using a high-resolution manometry catheter which provides greater resolution of the anal sphincter and puborectalis morphology, ${ }^{42}$ although this needs further confirmation.

Although dyssynergia patterns are reproducible ${ }^{39}$ and has high interobserver agreement rates especially for type $\mathrm{I}$ and $\mathrm{IV}^{43}$ several studies have found that these dyssynergic patterns were also observed in nearly $90 \%$ of asymptomatic controls and in chronic proctalgia without constipation. ${ }^{34,43}$ These findings are partly explained by a non-physiologic position during the test, ie, pushing in the left lateral position ${ }^{44}$ with an empty rectum. Effective explanation of the maneuvers and patient motivation during the test can provide accurate results. In one study, coaching increased the intrarectal pressure and increased the rectoanal pressure gradient during attempted defecation and changed the manometric findings from "pathologic" to "normal" values in 12/39 with dyssynergic defecation. ${ }^{45}$ However, it is unclear whether this coaching led to transient improvement or not. The prevalence of findings suggestive of abnormal defecation ranged from $14.9 \%$ for absent opening of the anorectal angle on defecography, to $47 \%$ for a dyssynergic pattern with manometry, and $52.9 \%$ for a dyssynergic pattern with ultrasonography. ${ }^{46}$ Thus, not only manometry but combined abnormalities with other modalities (ie, balloon expulsion, manometry, and imaging) are required for making a diagnosis of this condition (see diagnostic criteria below). Anorectal manometry facilitates measurements of the defecation index, which is a ratio of the intrarectal pressure and anal sphincter residual pressure. ${ }^{4,47}$ The defecation index serves as a simple and useful quantitative measure of rectoanal coordination during defecation. ${ }^{4,47}$ Also, sensory dysfunction may be present; both the threshold for first sensation and desire to defecate were higher in $60 \%$ of patients with dyssynergic defecation, ${ }^{4}$ and was associated with increased rectal compliance and rectal hyposen- sitivity.

\section{Balloon Expulsion Test}

This is an essential component of physiologic testing for dyssynergic defecation. In this test, a $4 \mathrm{~cm}$ long balloon filled with 50 $\mathrm{mL}$ of warm water is placed in the rectum. ${ }^{48}$ After placement, the patient is given privacy and asked to expel the balloon. A stop watch is provided to assess the time required for expulsion. Normal individuals can expel a balloon within one minute with this technique. ${ }^{48}$ However, the normal values for balloon expulsion time depend on body position and types of balloons. ${ }^{48,49}$ Although it is a useful screening test for dyssynergic defecation because of high specificity (80-90\%), its sensitivity is low $50 \%{ }^{49,50}$

\section{Defecography and Magnetic Resonance Defecography}

Defecography is a dynamic fluoroscopy study of evacuation performed in the sitting position, after placing $150 \mathrm{~mL}$ of barium paste into the patient's rectum. It provides useful information about structural changes such as rectoceles, rectal prolapse, and intussusception, and dyssynergic defecation and descending perineum syndrome. ${ }^{51}$ However, methodological differences and poor interobserver agreement has limited its overall usefulness. ${ }^{46}$

Magnetic resonance (MR) defecography or dynamic pelvic MRI can evaluate pelvic floor anatomy, dynamic motion, and rectal evacuation simultaneously. It provides an excellent resolution of anal sphincters, levator ani muscles and soft tissue surrounding the rectum without radiation exposure. ${ }^{52}$ Limitations include its high cost, lack of availability, and possible low sensitivity to detect rectal intussusception because it is more difficult to evacuate the contrast compared to barium defecography. ${ }^{53,54}$ Defecography or MR defecography are often used as an adjunct test when anorectal manometry and balloon expulsion tests are equivocal, or for patients with normal manometry but with prolonged balloon expulsion times. ${ }^{55}$

\section{Colonic Transit Study}

Colonic transit time can be measured by obtaining abdominal radiographs after patients ingest radio-opaque markers, ${ }^{56}$ a wireless motility capsule (WMC), ${ }^{57,58}$ or by scintigraphy. ${ }^{59}$ The WMC and scintigraphy can also measure gastric emptying and small intestinal transit, which may also be delayed in constipated patients. ${ }^{60}$ There is good diagnostic agreement between the WMC and radio-opaque markers technique, and WMC has been approved by the FDA for the assessment of colonic transit in patients with chronic constipation. $^{61}$

Up to two thirds of patients with a defecation disorder also 
have delayed colonic transit. ${ }^{25}$ Although, STC may coexist with dyssynergic defecation, a study in patients with both dyssynergia and slow colonic transit showed that colonic transit improved after dyssynergia treatment with biofeedback therapy. ${ }^{39}$ This suggests that outlet dysfunction is responsible for delayed colonic transit. Therefore, evaluation and treatment for dyssynergic defecation is recommended first in patients with chronic constipation, and further colonic or whole gut study is recommended if patients fail biofeedback therapy. ${ }^{55}$

\section{Diagnostic Criteria for Dyssynergic Defecation}

Diagnosis of dyssynergic defecation requires 3 components: first, the occurrence of constipation symptoms; second, manometric or electromyography (EMG) evidence of dyssynergic pattern during attempted defecation; and third, one other abnormal colorectal test such as the balloon expulsion test, defecography, or markers retention with colonic transit study. The current diagnostic criteria (Rome III) includes inadequate defecatory propulsion as another cause of a defecation disorder besides dyssynergic defecaton. ${ }^{9} \mathrm{~A}$ study showed that patients with inadequate defecatory propulsion or who cannot appropriately increase propulsive forces with or without contraction or less than $20 \%$ relaxation of anal sphincter during attempted defecation, demonstrated prolonged rectal balloon evacuation time and decreased pelvic floor descent on defecography. ${ }^{62}$ Patients with constipation-predominant IBS are not eligible to be diagnosed with defecatory disorders by this Rome III diagnostic

Box 1. Proposed Diagnostic Criteria for Dyssynergic Defecation

- Patients must satisfy the diagnostic criteria for functional constipation and/or constipation-predominant IBS.

- Patients must demonstrate dyssynergic pattern during repeated attempts to defecate.

A dyssynergic pattern of defecation (Types I-IV) is defined as a paradoxical increase in anal sphincter pressure (anal contraction), or less than $20 \%$ relaxation of the resting anal sphincter pressure, or inadequate propulsive forces observed with manometry, imaging or electromyographic recordings

- Patients must satisfy one or more of the following criteria*

- Inability to expel an artificial stool (50 mL water-filled balloon) within 1-2 minutes.

- Inability to evacuate or $\geq 50 \%$ retention of barium during defecography.

* Some laboratories use a prolonged colonic transit time, ie, greater than 5 markers ( $\geq 20 \%$ marker retention) on a plain abdominal radiography taken 120 hours after ingestion of one radio-opaque marker capsule containing 24 radio-opaque markers. criteria. ${ }^{9}$ However, an association between IBS and defecation disorders has been recognized and can be effectively treated with biofeedback therapy irrespective of coexistent IBS. ${ }^{18,33}$ So, the new Rome IV diagnostic criteria includes IBS with constipation patients in a proposed new diagnostic criteria (Box 1).

\section{Treatment}

The treatment should be customized for each individual, taking into consideration patient's symptoms, underlying pathophysiology, age, co-morbid conditions, patient's concerns and expectations. Dyssynergic defecation treatment consists of (1) standard treatment for constipation, (2) biofeedback therapy, and (3) other measures including botulinum toxin injection, myectomy, or ileostomy.

\section{Standard Treatment}

This should consist of a detailed clinical assessment and correction of coexisting issues such as avoiding constipating medications, adequate fiber (up to $25 \mathrm{~g}$ per day) and fluid intake, and regular exercise. These life style modifications can be useful although there is limited evidence to support this. ${ }^{63}$ In addition, they should be encouraged to capitalize on mechanisms that stimulate the colon, ${ }^{64}$ such as after waking and after a meal and avoid postponing defecation, as the urge subsides after a few minutes and may not return for hours. Patients should receive instructions regarding timed toilet training and effective straining methods. Timed toilet training consists of educating the patient to attempt a bowel movement at least twice a day, usually 30 minutes after meals. During attempted defecation, they must be instructed to push at a 50-70\% of their maximum effort of straining and to strain for no more than 5 minutes. It is important to emphasize that stool impaction should be prevented at all costs. Patients should be advised to refrain from digital disimpaction of stools.

\section{Fiber supplements}

Fiber accelerates colonic transit and bulks the stool either by drawing fluid to colonic lumen or by facilitating fermentation and affecting gut microbiota or epithelial permeability. ${ }^{65}$ A systematic review on the effects of fiber in chronic constipation showed that fiber is beneficial for mild to moderate constipation and constipation predominant IBS. It improved global symptoms, decreased straining, increased stool frequency, softened stool consistency, and decreased laxative uses. ${ }^{66}$ Although most of the studies used soluble fiber, such as psyllium, there is limited evidence that insoluble fiber, such as calcium polycarbophil, bran and methylcellulose, and mixed 
fiber supplements that contain both soluble and insoluble fiber as well as natural dietary fiber, such as prunes, are effective. ${ }^{66}$ It is important to recommend patients to take adequate water intake while taking fibers to avoid hard and bulky stools, and to inform them about adverse effects including bloating, flatulence, and abdominal discomfort. ${ }^{67}$ The benefits of adding fibers are not evident for days to weeks. ${ }^{67} \mathrm{~A}$ study showed that patients with slow colonic transit or dyssynergic defecation respond poorly to 30 grams of fiber supplementation per day, whereas those without an underlying motility disorder improved.$^{68}$ Patients with fecal impaction, or those confined to the bed or requiring fluid restriction should not be given fiber supplements. ${ }^{67}$

\section{Pharmacologic Approaches}

Laxatives and newer drugs such as intestinal secretagogues and serotonergic enterokinetic agents, have not been systematically evaluated in patients with dyssynergic defecation, but they can be effective and can be used as an adjunctive treatment along with biofeedback therapy, especially in patients with slow colonic transit or IBS. Long term follow-up studies show that after biofeedback therapy, the proportion of patients using laxatives decreases over time. ${ }^{69}$

\section{New drugs for constipation}

Linaclotide and lubiprostone are effective in chronic constipation and constipation-predominant IBS. ${ }^{70,71}$ Prucalopride, a 5-HT receptor agonist, is effective and well-tolerated for treatment of chronic constipation at a dose of $2 \mathrm{mg} /$ day for adults and $1 \mathrm{mg} /$ day for those over 65 years of age. ${ }^{72}$ These new drugs have not been assessed in dyssynergic defecation.

\section{Biofeedback Therapy}

Biofeedback therapy is the mainstay for treatment of dyssynergic defecation. It is an instrument-based "operant conditioning" technique. The goals are (1) to correct the dyssynergia or incoordination of abdominal and pelvic floor muscles during evacuation, and (2) to improve perception of rectal filling in patients with impaired rectal sensation.

Its treatment efficacy is $70-80 \%$ in randomized controlled trials (RCTs) and it is more effective than sham therapy, polyethylene glycol or diazepam. ${ }^{73-76}$ Long term studies have shown that the efficacy is maintained for more than 2 years after treatment. ${ }^{69,73,76}$ $\mathrm{Rao}^{77}$ described 3 phases of the biofeedback therapy for constipation protocol which consisted of (1) patient evaluation/education, (2) active phase of therapy (6 sessions), and (3) reinforcement (3 sessions) (Box 2). On average, 4 to 6 sessions lasting 60 minutes each, about 2 weeks apart, are required for training, ${ }^{73-76}$ although this should be customized for each patient. Training can be discontinued if the patient's difficult defecation symptoms have improved and the patient can consistently demonstrate, over 2 consecutive training sessions, a normal pattern of defecation with at least $50 \%$ of attempts. ${ }^{77}$ The success of biofeedback therapy depends on both the patient's motivation and the skill of the biofeedback therapist. There are limited studies determining the predictive factors for biofeedback therapy response, and these studies used different biofeedback techniques and treatment outcome measurements. ${ }^{18,73,78}$ Demographic features, overlapping IBS, and prolonged balloon expulsion time were not associated with poor biofeedback therapy response whereas symptom severity, use of the digital maneuver, presence of abnormal rectal sensation, and presence of delayed colonic transit showed conflicting results. ${ }^{18,73,78}$ On the strength of the current evidence, biofeedback therapy has been assigned as a grade A recommendation for the treatment of dyssynergic defecation by the American Neurogastroenterology and Motility Society and the European Society of Neurogastroenterology and Motility. ${ }^{79}$ Table demonstrates the efficacy of biofeedback therapy in RCTs and Figure 2 demonstrates anorectal manometry findings, before and after biofeedback therapy in patients with dyssynergic defecation.

\section{Biofeedback Therapy Equipment}

The instrument for providing feedback may include a solidstate manometry probe, electromyography probe, simulated balloon or a home biofeedback training device. ${ }^{77}$

The solid-state manometry probe with microtransducers and a balloon is ideally suited for biofeedback therapy. Here, the transducers that are located in the rectum and anal canal provide a visual

Box 2. Biofeedback Therapy for Dyssynergic Defecation Protocol

- Phase I: Evaluation/education

- Symptom assessment (visual analog scale), stool diary

- Explain physiology of defecation and pathophysiology of dyssynergic defecation

- Diaphragmatic breathing exercises

- Timed toilet training

- Phase II: Active phase of biofeedback therapy

- Visual/auditory/verbal feedback techniques

- Duration of 30-60 minutes each in 1-2 weeks apart for 4-6 sessions

- Home devices

- Phase III: Reinforcement

- At 6th weeks, 3rd, 6th, and 12th months 


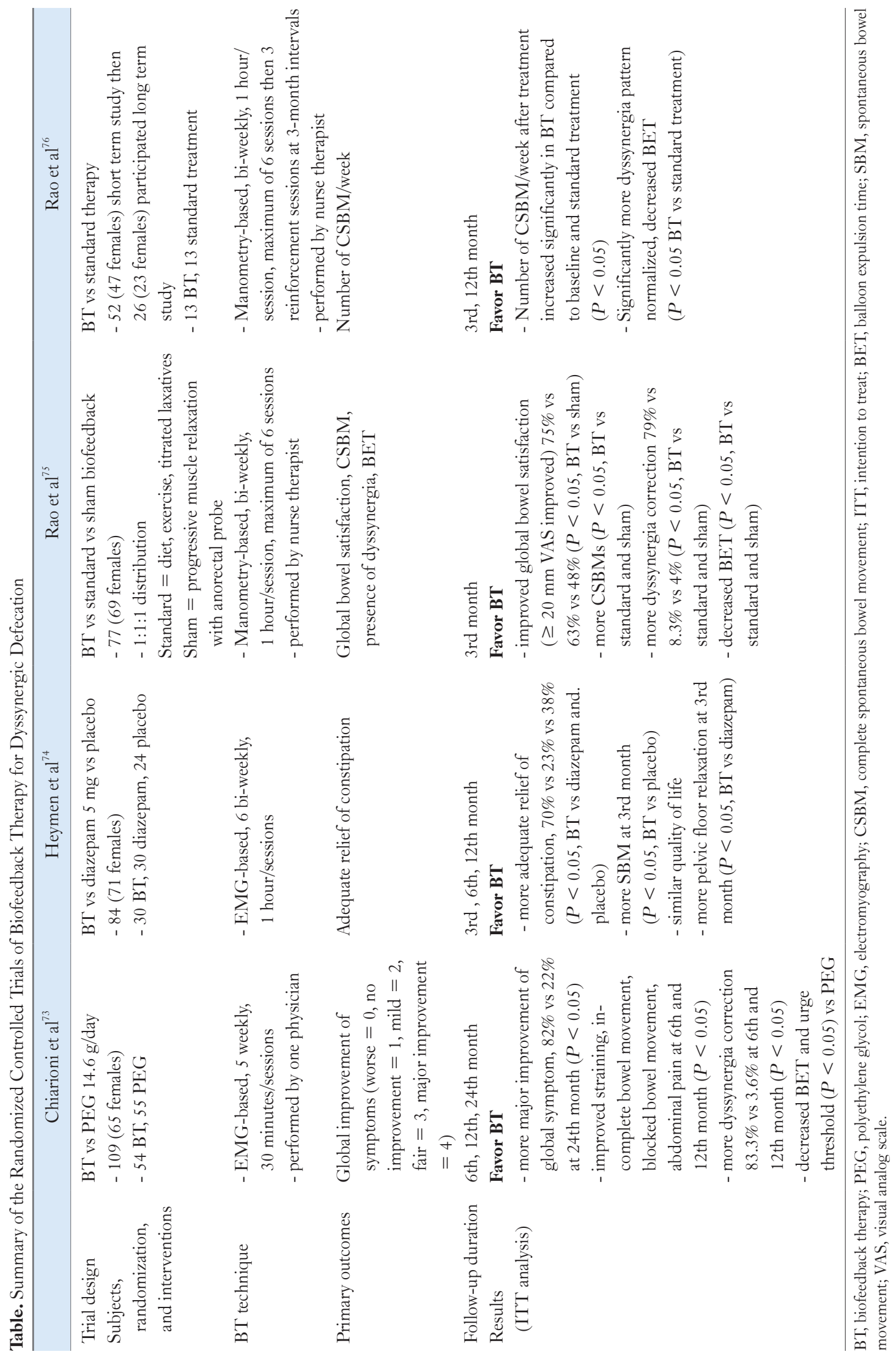



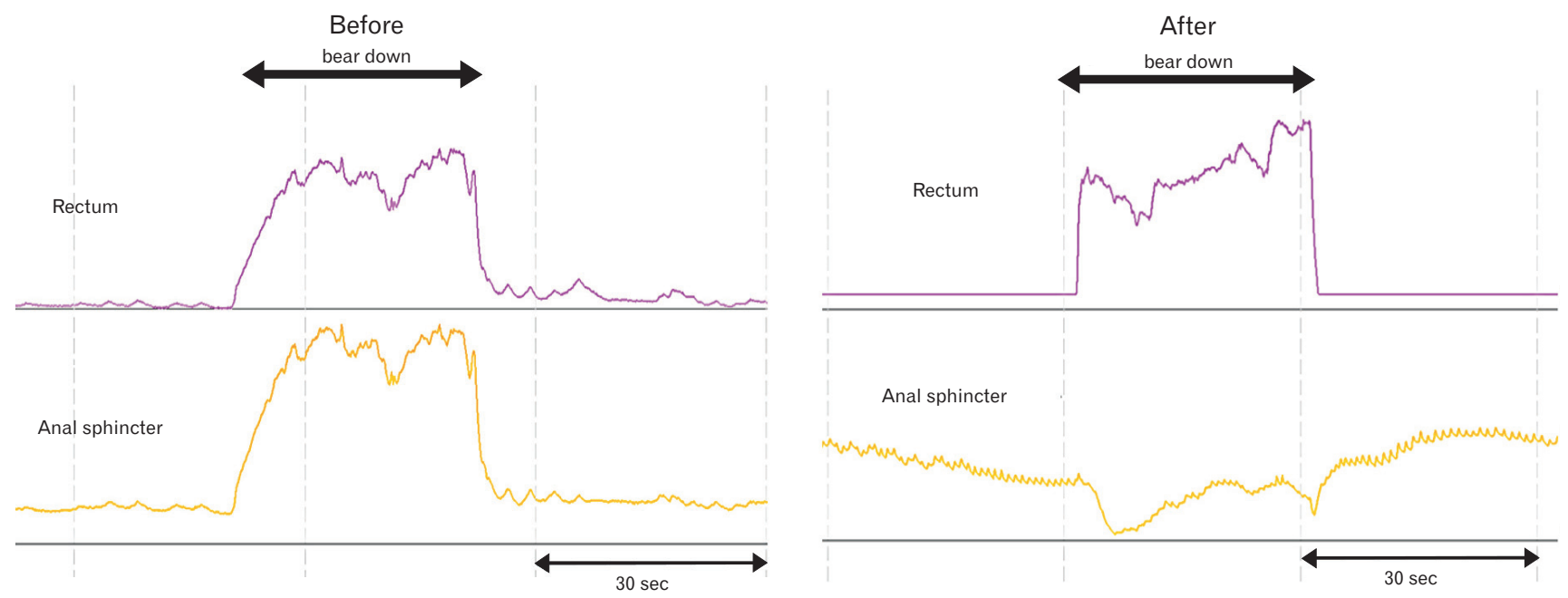

Figure 2. The rectal and anal sphincter pressure changes, and manometric patterns in a patient with constipation and dyssynergic defecation, before and after biofeedback therapy.

display of pressure activity throughout the anorectum. Alternatively, an EMG biofeedback system that consists of a surface EMG electrode that is mounted on a probe or affixed to the surface of the external anal sphincter muscle can be used..$^{73,74}$ The pitch of the auditory signals can be used to provide instant feedback regarding the changes in electrical activity of the anal sphincter beside the visual feedback from the monitor. Home training devices largely use an EMG home trainer or silicon probe device attached to a hand-held monitor. A prospective RCT that employed home trainers demonstrated that home training was as effective as office based training. ${ }^{80}$ In another European study, significant symptom improvement was reported in most subjects receiving home therapy. ${ }^{6}$

\section{Biofeedback Techniques}

\section{Improve or correct dyssynergia}

This training consists of improving rectoanal coordination during defecation followed by simulated defecation training.

Rectoanal coordination. The purpose of this training is to produce an adequate abdominal push effort as reflected by a rise in intra-rectal pressure on the manometric tracing that is synchronized with relaxation of the pelvic floor and anal canal as depicted by a decrease in anal sphincter pressure (Fig. 2). To facilitate this training, ideally the subject should be seated on a commode which is the usual position for defecation. After correcting the patient's posture (for example, keeping the legs apart as opposed to keeping them together) and the sitting angle at which he/she will attempt the def- ecation maneuver (ie, leaning forward), the subject is asked to take a good diaphragmatic breath and to push and bear down as if to defecate. During the attempted defecation, the patient is instructed to titrate the degree of abdominal push and the anal sphincter relaxation effort and in particular not to push excessively, as this is often counterproductive and leads to voluntary withholding. The visual display of the pressure changes in the rectum and anal canal on the monitor together with verbal feedback by the therapist provide instant feedback to the patient regarding their performance and help them to understand and learn quickly.

Next, the balloon in the rectum is distended with $60 \mathrm{cc}$ of air to provide the subject with a sensation of rectal fullness or desire to defecate. As soon as the subject experiences this desire, he/she is then encouraged to push and attempt defecation. After each attempt, the balloon is deflated and re-inflated prior to the next attempt. At least 10-15 maneuvers are performed for each step. If using an EMG device, the goal is to teach the subject to either reduce the amplitude of electrical wave forms on the monitor or to decrease the intensity of sound signals. ${ }^{73,74}$

Simulated defecation training. The goal of this training is to teach the subject to expel an artificial stool in the laboratory using the correct technique. This maneuver is performed by placing a 50 $\mathrm{mL}$ water-filled balloon in the rectum, then sit on a commode and attempt defecation. ${ }^{75}$ If the subject is unable to expel the balloon, gentle traction is applied to the balloon to supplement the patient's effort. Gradually, the subject learns how to coordinate the defecation maneuver and to expel the balloon. 


\section{Rectal sensory training}

The goal of this training is to improve the thresholds for rectal sensory perception and to promote better awareness for stooling. The patients aim to perceive a particular volume of balloon distention but with the same intensity as they had previously experienced with a larger volume of balloon distention. The first step here is to progressively inflate the balloon until the subject experiences an urge to defecate. Then, this threshold volume is noted. The maneuver is repeated 2 or 3 times with this volume to educate the subject and to trigger appropriate rectal sensations. Thereafter, with each subsequent inflation, the balloon volume is decreased in a stepwise manner by about $10 \%$. During each distention, the subject is encouraged to observe the monitor and to note the pressure changes in the rectum and simultaneously pay close attention to the sensation they are experiencing in the rectum. They are encouraged to use the visual cues for volumes that are either not readily perceived or only faintly perceived. By the end of each session, newer thresholds for rectal perception are established. Rectal sensory training can be performed with a hand-held syringe attached to the manometry catheter with a rectal balloon, or with a barostat. A recent RCT showed that barostat-assisted sensory training is superior to syringe-assisted training, and $80 \%$ of patients with rectal hyposensitivity achieved successful outcome. ${ }^{81}$

\section{Other Measures for Dyssynergic Defecation Treatment}

Other methods, including myectomy, botulinum toxin injection or surgery, have been shown to be less effective than biofeedback therapy. ${ }^{29,82}$ Injection of botulinum toxin into the anal sphincter has been tried with mixed results. ${ }^{29,83}$ In both of these studies there was some improvement in less than one half of patients but troublesome incontinence occurred in one study. ${ }^{83}$ Botulinum toxin seems to be useful in children. ${ }^{79}$

\section{Summary}

Constipation caused by dyssynergic defecation is common. Today, it is possible to accurately diagnose this problem through history taking, prospective stool diaries, DRE and anorectal physiologic tests. RCTs have demonstrated that biofeedback therapy is not only efficacious but superior to other modalities both in the short term and long term management. Also, symptom improvement is due to a change in the underlying pathophysiology. Development of userfriendly methods of biofeedback therapy including the use of home biofeedback devices will significantly enhance the adoption of this treatment. Improved reimbursement for this treatment will have a significant impact, and could be transformational for patients with this common form of constipation.

\section{Financial support: None.}

\section{Conflicts of interest: None.}

Author contributions: Satish Rao provided planning and overall design of the article and wrote several portions of the manuscript, proofed and revised the final version; and Tanisa Patcharatrakul assisted with writing some portions of the manuscript, helped with making tables and figures and updating references.

\section{References}

1. Rao SS. Dyssynergic defecation and biofeedback therapy. Gastroenterol Clin North Am 2008;37:569-586.

2. Preston DM, Lennard-Jones JE. Anismus in chronic constipation. Dig Dis Sci 1985;30:413-418.

3. Whitehead WE, Wald A, Diamant NE, Enck P, Pemberton JH, Rao SS. Functional disorders of the anus and rectum. Gut 1999;45(suppl 2): II55-II59.

4. Rao SS, Welcher KD, Leistikow JS. Obstructive defecation: a failure of rectoanal coordination. Am J Gastroenterol 1998;93:1042-1050.

5. Glia A, Gylin M, Gullberg K, Lindberg G. Biofeedback retraining in patients with functional constipation and paradoxical puborectalis contraction: comparison of anal manometry and sphincter electromyography for feedback. Dis Colon Rectum 1997;40:889-895.

6. Kawimbe BM, Papachrysostomou M, Binnie NR, Clare N, Smith AN. Outlet obstruction constipation (anismus) managed by biofeedback. Gut 1991;32:1175-1179.

7. Bleijenberg G, Kuijpers HC. Treatment of the spastic pelvic floor syndrome with biofeedback. Dis Colon Rectum 1987;30:108-111.

8. Rao SS, Tuteja AK, Vellema T, Kempf J, Stessman M. Dyssynergic defecation: demographics, symptoms, stool patterns, and quality of life. J Clin Gastroenterol 2004;38:680-685.

9. Bharucha AE, Wald A, Enck P, Rao S. Functional anorectal disorders. Gastroenterology 2006;130:1510-1518.

10. Suares NC, Ford AC. Prevalence of, and risk factors for, chronic idiopathic constipation in the community: systematic review and metaanalysis. Am J Gastroenterol 2011;106:1582-1591.

11. Sonnenberg A, Koch TR. Physician visits in the United States for constipation: 1958 to 1986. Dig Dis Sci 1989;34:606-611.

12. Talley NJ, O'Keefe EA, Zinsmeister AR, Melton LJ 3rd. Prevalence of gastrointestinal symptoms in the elderly: a population-based study. Gastroenterology 1992;102:895-901.

13. Choung RS, Locke GR 3rd, Rey E, et al. Factors associated with persis- 
tent and nonpersistent chronic constipation, over 20 years. Clin Gastroenterol Hepatol 2012;10:494-500.

14. Bradley CS, Kennedy CM, Turcea AM, Rao SS, Nygaard IE. Constipation in pregnancy: prevalence, symptoms, and risk factors. Obstet Gynecol 2007;110:1351-1357.

15. Choung RS, Rey E, Richard Locke G 3rd, et al. Chronic constipation and co-morbidities: A prospective population-based nested case-control study. United European Gastroenterol J 2016;4:142-151.

16. Mertz H, Naliboff B, Mayer E. Physiology of refractory chronic constipation. Am J Gastroenterol 1999;94:609-615.

17. Nyam DC, Pemberton JH, Ilstrup DM, Rath DM. Long-term results of surgery for chronic constipation. Dis Colon Rectum 1997;40:273-279.

18. Patcharatrakul T, Gonlachanvit S. Outcome of biofeedback therapy in dyssynergic defecation patients with and without irritable bowel syndrome. J Clin Gastroenterol 2011;45:593-598.

19. Nellesen D, Yee K, Chawla A, Lewis BE, Carson RT. A systematic review of the economic and humanistic burden of illness in irritable bowel syndrome and chronic constipation. J Manag Care Pharm 2013;19:755764.

20. Dennison C, Prasad M, Lloyd A, Bhattacharyya SK, Dhawan R, Coyne $\mathrm{K}$. The health-related quality of life and economic burden of constipation. Pharmacoeconomics 2005;23:461-476.

21. Heidelbaugh JJ, Stelwagon M, Miller SA, Shea EP, Chey WD. The spectrum of constipation-predominant irritable bowel syndrome and chronic idiopathic constipation: US survey assessing symptoms, care seeking, and disease burden. Am J Gastroenterol 2015;110:580-587.

22. Sethi S, Mikami S, Leclair J, et al. Inpatient burden of constipation in the United States: an analysis of national trends in the United States from 1997 to 2010. Am J Gastroenterol 2014;109:250-256.

23. Nyrop KA, Palsson OS, Levy RL, et al. Costs of health care for irritable bowel syndrome, chronic constipation, functional diarrhoea and functional abdominal pain. Aliment Pharmacol Ther 2007;26:237-248.

24. Rao SS, Seaton K, Miller MJ, et al. Psychological profiles and quality of life differ between patients with dyssynergia and those with slow transit constipation. J Psychosom Res 2007;63:441-449.

25. Rao SS, Tuteja AK, Vellema T, Kempf J, Stessman M. Dyssynergic defecation: demographics, symptoms, stool patterns, and quality of life. J Clin Gastroenterol 2004;38:680-685.

26. Leroi AM, Berkelmans I, Denis P, Hémond M, Devroede G. Anismus as a marker of sexual abuse. Consequences of abuse on anorectal motility. Dig Dis Sci 1995;40:1411-1416.

27. Ringel Y, Whitehead WE, Toner BB, et al. Sexual and physical abuse are not associated with rectal hypersensitivity in patients with irritable bowel syndrome. Gut 2004;53:838-842.

28. Pinho M, Yoshioka K, Keighley MR. Long term results of anorectal myectomy for chronic constipation. Br J Surg 1989;76:1163-1164.

29. Ron Y, Avni Y, Lukovetski A, et al. Botulinum toxin type-A in therapy of patients with anismus. Dis Colon Rectum 2001;44:1821-1826.

30. Ratuapli S, Bharucha AE, Noelting J, Harvey D, Zinsmeister AR. Phenotypic identification and classification of functional defecatory disorders using high-resolution anorectal manometry. Gastroenterology
2013;144:314-322, e2.

31. Glia A, Lindberg G, Nilsson LH, Mihocsa L, Akerlund JE. Clinical value of symptom assessment in patients with constipation. Dis Colon Rectum 1999;42:1401-1408; discussion 1408-1410.

32. Koch A, Voderholzer WA, Klauser AG, Müller-Lissner S. Symptoms in chronic constipation. Dis Colon Rectum. 1997;40:902-906.

33. Suttor VP, Prott GM, Hansen RD, Kellow JE, Malcolm A. Evidence for pelvic floor dyssynergia in patients with irritable bowel syndrome. Dis Colon Rectum 2010;53:156-160.

34. Chiarioni G, Nardo A, Vantini I, Romito A, Whitehead W. Biofeedback is superior to electrogalvanic stimulation and massage for treatment of levator ani syndrome. Gastroenterology 2010;138:1321-1329.

35. Rao SS, Ozturk R, De Ocampo S, Stessman M. Pathophysiology and role of biofeedback therapy in solitary rectal ulcer syndrome. Am J Gastroenterol 2006;101:613-618.

36. Wald A, Chandra R, Chiponis D, Gabel S. Anorectal function and continence mechanisms in childhood encopresis. J Pediatr Gastroenterol Nutr 1986;5:346-351.

37. Chitkara DK, van Tilburg MA, Blois-Martin N, Whitehead WE. Early life risk factors that contribute to irritable bowel syndrome in adults: a systematic review. Am J Gastroenterol 2008;103:765-774.

38. Chiarioni G, Bassotti G, Monsignori A, et al. Anorectal dysfunction in constipated women with anorexia nervosa. Mayo Clin Proc 2000; 75:1015-1019.

39. Rao SS, Mudipalli RS, Stessman M, Zimmerman B. Investigation of the utility of colorectal function tests and Rome II criteria in dyssynergic defecation (Anismus). Neurogastroenterol Motil 2004;16:589-596.

40. Tantiphlachiva K, Rao P, Attaluri A, Rao SS. Digital rectal examination is a useful tool for identifying patients with dyssynergia. Clin Gastroenterol Hepatol 2010;8:955-960.

41. Wong RK, Drossman DA, Bharucha AE, et al. The digital rectal examination: a multicenter survey of physicians' and students' perceptions and practice patterns. Am J Gastroenterol 2012;107:1157-1163.

42. Rao SS, Leelasinjaroen P, Amieva-Balmori M, Sharma A, Patcharatrakul T, Dewitt A. Characterization of dyssynergia phenotypes with high resolution anorectal manometry (HRAM). Gastroenterology 2016;150 (in press)

43. Grossi U, Carrington EV, Bharucha AE, Horrocks EJ, Scott SM, Knowles CH. Diagnostic accuracy study of anorectal manometry for diagnosis of dyssynergic defecation. Gut 2016;65:447-455.

44. Rao SS, Kavlock R, Rao S. Influence of body position and stool characteristics on defecation in humans. Am J Gastroenterol 2006;101:27902796.

45. Heinrich H, Fruehauf H, Sauter M, et al. The effect of standard compared to enhanced instruction and verbal feedback on anorectal manometry measurements. Neurogastroenterol Motil 2013;25:230-237, e163.

46. Videlock EJ, Lembo A, Cremonini F. Diagnostic testing for dyssynergic defecation in chronic constipation: meta-analysis. Neurogastroenterol Motil. 2013;25:509-520.

47. Rao SS, Hatfield R, Soffer E, Rao S, Beaty J, Conklin JL. Manometric tests of anorectal function in healthy adults. Am J Gastroenterol 
1999;94:773-783.

48. Remes-Troche JM, Rao SS. Diagnostic testing in patients with chronic constipation. Curr Gastroenterol Rep 2006;8:416-424.

49. Rao SS, Ozturk R, Laine L. Clinical utility of diagnostic tests for constipation in adults: a systematic review. Am J Gastroenterol 2005;100:16051615.

50. Chiarioni G, Kim SM, Vantini I, Whitehead WE. Validation of the balloon evacuation test: reproducibility and agreement with findings from anorectal manometry and electromyography. Clin Gastroenterol Hepatol 2014;12:2049-2054.

51. Savoye-Collet C, Koning E, Dacher JN. Radiologic evaluation of pelvic floor disorders. Gastroenterol Clin North Am 2008;37:553-567.

52. Lalwani N, Moshiri M, Lee JH, Bhargava P, Dighe MK. Magnetic resonance imaging of pelvic floor dysfunction. Radiol Clin North Am 2013;51:1127-1139.

53. Pilkington SA, Nugent KP, Brenner J, et al. Barium proctography vs magnetic resonance proctography for pelvic floor disorders: a comparative study. Colorectal Dis 2012;14:1224-1230.

54. Schreyer AG, Paetzel C, Fürst A, et al. Dynamic magnetic resonance defecography in 10 asymptomatic volunteers. World J Gastroenterol 2012;18:6836-6842.

55. Wald A, Bharucha AE, Cosman BC, Whitehead WE. ACG clinical guideline: management of benign anorectal disorders. Am J Gastroenterol 2014;109:1141-1157.

56. Metcalf AM, Phillips SF, Zinsmeister AR, MacCarty RL, Beart RW, Wolff BG. Simplified assessment of segmental colonic transit. Gastroenterology 1987;92:40-47.

57. Rao SS, Kuo B, McCallum RW, et al. Investigation of colonic and whole-gut transit with wireless motility capsule and radiopaque markers in constipation. Clin Gastroenterol Hepatol 2009;7:537-544.

58. Camilleri M, Thorne NK, Ringel Y, et al. Wireless pH-motility capsule for colonic transit: prospective comparison with radiopaque markers in chronic constipation. Neurogastroenterol Motil 2010;22:874-882, 233.

59. Stivland T, Camilleri M, Vassallo M, et al. Scintigraphic measurement of regional gut transit in idiopathic constipation. Gastroenterology 1991;101:107-115.

60. Rao SS, Coss-Adame E, Valestin J, Mysore K. Evaluation of constipation in older adults: radioopaque markers (ROMs) versus wireless motility capsule (WMC). Arch Gerontol Geriatr 2012;55:289-294

61. Rao SS, Camilleri M, Hasler WL, et al. Evaluation of gastrointestinal transit in clinical practice: position paper of the American and European Neurogastroenterology and Motility Societies. Neurogastroenterol Motil 2011;23:8-23.

62. Halligan S, Thomas J, Bartram C. Intrarectal pressures and balloon expulsion related to evacuation proctography. Gut 1995;37:100-104.

63. Müller-Lissner SA, Kamm MA, Scarpignato C, Wald A. Myths and misconceptions about chronic constipation. Am J Gastroenterol 2005;100:232-242.

64. Bassotti G, Gaburri M. Manometric investigation of high-amplitude propagated contractile activity of the human colon. Am J Physiol 1988; 255(5 Pt 1):G660-G664.

65. Stephen AM, Cummings JH. Mechanism of action of dietary fibre in the human colon. Nature 1980;284:283-284

66. Rao SS, Yu S, Fedewa A. Systematic review: dietary fibre and FODMAP-restricted diet in the management of constipation and irritable bowel syndrome. Aliment Pharmacol Ther 2015;41:1256-1270.

67. Bharucha AE, Pemberton JH, Locke GR 3rd. American Gastroenterological Association technical review on constipation. Gastroenterology 2013;144:218-238.

68. Voderholzer WA, Schatke W, Mühldorfer BE, Klauser AG, Birkner B, Müller-Lissner SA. Clinical response to dietary fiber treatment of chronic constipation. Am J Gastroenterol 1997;92:95-98.

69. Lee HJ, Boo SJ, Jung KW, et al. Long-term efficacy of biofeedback therapy in patients with dyssynergic defecation: results of a median 44 months follow-up. Neurogastroenterol Motil 2015;27:787-795.

70. Ford AC, Suares NC. Effect of laxatives and pharmacological therapies in chronic idiopathic constipation: systematic review and meta-analysis. Gut 2011;60:209-218.

71. Ford AC, Moayyedi P, Lacy BE, et al. American College of Gastroenterology monograph on the management of irritable bowel syndrome and chronic idiopathic constipation. Am J Gastroenterol 2014;109(suppl 1):S2-S26.

72. Shin A, Camilleri M, Kolar G, Erwin P, West CP, Murad MH. Systematic review with meta-analysis: highly selective 5-HT4 agonists (prucalopride, velusetrag or naronapride) in chronic constipation. Aliment Pharmacol Ther 2014;39:239-253.

73. Chiarioni G, Whitehead WE, Pezza V, Morelli A, Bassotti G. Biofeedback is superior to laxatives for normal transit constipation due to pelvic floor dyssynergia. Gastroenterology 2006;130:657-664.

74. Heymen S, Scarlett Y, Jones K, Ringel Y, Drossman D, Whitehead WE. Randomized, controlled trial shows biofeedback to be superior to alternative treatments for patients with pelvic floor dyssynergia-type constipation. Dis Colon Rectum 2007;50:428-441.

75. Rao SS, Seaton K, Miller M, et al. Randomized controlled trial of biofeedback, sham feedback, and standard therapy for dyssynergic defecation. Clin Gastroenterol Hepatol 2007;5:331-338.

76. Rao SS, Valestin J, Brown CK, Zimmerman B, Schulze K. Long-term efficacy of biofeedback therapy for dyssynergic defecation: randomized controlled trial. Am J Gastroenterol 2010;105:890-896.

77. Rao SS. Biofeedback therapy for constipation in adults. Best Pract Res Clin Gastroenterol 2011;25:159-166.

78. Patcharatrakul T, Valestin J, Schmeltz A, Schulze K, Rao SS. Factors that predict outcome of biofeedback therapy in constipation with dyssynergic defecation (DD). Gastroenterology 2016 (in press)

79. Rao SS, Benninga MA, Bharucha AE, Chiarioni G, Di Lorenzo C, Whitehead WE. ANMS-ESNM position paper and consensus guidelines on biofeedback therapy for anorectal disorders. Neurogastroenterol Motil 2015;27:594-609.

80. Rao SS, Valestin J, Brown CK, et al. Home or office biofeedback therapy for dyssynergic defecation - randomized controlled trial. Gastroenterology 2011;140(suppl 1):S160.

81. Rao SS, Erdogan A, Coss-Adame E, Valestin J, Mattos ML. Rectal hyposensitivity: randomized controlled trial of barostat vs. syringe-assisted sensory training. Gastroenterology 2013;144(suppl 1):S363. 
82. Podzemny V, Pescatori LC, Pescatori M. Management of obstructed defecation. World J Gastroenterol 2015;21:1053-1060.

83. Hallan RI, Williams NS, Melling J, Waldron DJ, Womack NR, Mor- rison JF. Treatment of anismus in intractable constipation with botulinum A toxin. Lancet 1988;2:714-717. 